Retraction

\title{
Retraction: Nebhen, J., et al. Constant Temperature Anemometer with Self-Calibration Closed Loop Circuit. Appl. Sci. 2020, 10, 3405
}

\author{
Applied Sciences Editorial Office \\ MDPI, St. Alban-Anlage 66, 4052 Basel, Switzerland; applsci@mdpi.com
}

Received: 20 October 2020; Accepted: 28 October 2020; Published: 11 November 2020

In the published paper [1], Figure 1 is identical to Figure 1a published in the journal Applied Physics Letters [2], Table 1 is similar to Table 1 published in the journal Sensors and Actuators A: Physical [3], and Figure 2 is identical to Figure 3a published in the journal Applied Physics Letter [2] and Figure 1b published in the journal Experiments in Fluids [4]. The text from the Introduction is identical to the contents published in the journal Sensors and Actuators A: Physical [3]. The text from Section 2 is similar to the contents published in the journal Sensors and Actuators A: Physical [3]. The authors provided explanations for the similarities that were not accepted by the journal editor. After thorough investigation, the journal has therefore made the decision to retract the paper [1]. The Editor-in-Chief and Editorial Office of the Applied Sciences have checked the case, and the Editor-in-Chief has approved the retraction.

The Applied Sciences Editorial Office apologize to the readers of Applied Sciences for any inconvenience caused. To ensure the addition of only high-quality scientific works to the field of scholarly communication, this paper [1] is retracted and shall be marked accordingly. MDPI is a member of the Committee on Publication Ethics (COPE) and takes very seriously the responsibility to enforce strict ethical policies and standards.

\section{References}

1. Nebhen, J.; Alnowaiser, K.; Mansouri, S. Constant Temperature Anemometer with Self-Calibration Closed Loop Circuit. Appl. Sci. 2020, 10, 3405. [CrossRef]

2. Ghouila-Houri, C.; Claudel, J.; Gerbedoen, J.-C.; Gallas, Q.; Garnier, E.; Merlen, A.; Viard, R.; Talbi, A.; Pernod, P. High temperature gradient micro-sensor for wall shear stress and flow direction measurements. Appl. Phys. Lett. 2016, 109, 241905. [CrossRef]

3. Ghouila-Houri, C.; Gallas, Q.; Garnier, E.; Merlen, A.; Viard, R.; Talbi, A.; Pernod, P. High temperature gradient calorimetric wall shear stress micro-sensor for flow separation detection. Sens. Actuators A Phys. 2017, 266, 232-241. [CrossRef]

4. Ghouila-Houri, C.; Talbi, A.; Viard, R.; Gallas, Q.; Garnier, E.; Merlen, A.; Pernod, P. Unsteady flows measurements using a calorimetric wall shear stress micro-sensor. Exp. Fluids 2019, 60, 67. [CrossRef]

Publisher's Note: MDPI stays neutral with regard to jurisdictional claims in published maps and institutional affiliations.

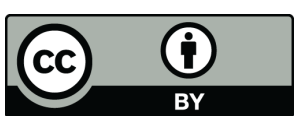

(C) 2020 by the author. Licensee MDPI, Basel, Switzerland. This article is an open access article distributed under the terms and conditions of the Creative Commons Attribution (CC BY) license (http://creativecommons.org/licenses/by/4.0/). 